Goldschmidt 2021 Abstract

https://doi.org/10.7185/gold2021.5449

\section{ADVECTION AND DISPERSION OF ARSENIC AT THE BAGNOLI BAY BY A SEMI-ANTHROPOGENIC SOURCE.}

\author{
MARIANO BUCCINO ${ }^{1}$, MOHAMMAD DALIRI ${ }^{1}$, MARIO \\ CALABRESE $^{1}$ AND RENATO SOMMA $^{2}$ \\ ${ }^{1}$ University of Napoli Federico II \\ ${ }^{2}$ Istituto Nazionale di Geofisica e Vulcanologia (INGV) \\ Presenting Author: buccino@unina.it
}

Bagnoli-Coroglio is an urban district of the city of Napoli, which has been the site of heavy industrialization for nearly one century . In the late ' $900 \mathrm{~s}$, it was classified by the Italian Government as a site to be remediated and restored to its natural beauty. This gave rise to intense research work, which culminated in the project $\mathrm{ABBaCo}$, targeting the expertise of scientists from different fields, towards innovative solutions for the environmental recovery of the site [1].

Within the ABBaCo's frame, a collaboration has been established between researchers of the University of Naples Federico II and those of the Italian Institute of Geophysics and Volcanology, aimed to individuate the possible sources of the contamination by arsenic, affecting marine sediments.

Attention has been drawn to the role of the Agnano Effluent, a channel outfalling at the westernmost part of the Bagnoli coast, which conveys to the sea the water of a number of hot springs, originating at the volcanic Agnano area.

Differently from other studies, which used statistically based approaches [2], this research has been carried out via numerical simulations. The numerical study encompasses either the analysis of the flow regime at the bay or the detailed simulation of transport, dispersion, diffusion and settling of the released arsenic.

Results of the research reveal that a primary role in the As advection could be played by a rip current system, which takes place under both NE and SE winds and borders the high As contamination contour (Figure 1).

Good agreement has been found between As measurements and simulations, especially under SW winds accompained by mild wave attacks (Figure 2).

\section{REFERENCES}

[1] Buccino, M, del Vita, I, Calabrese, M (2014). "Engineering Modeling of Wave Transmission of Reef Balls". Journal of Waterway, Port,Coastal and Ocean Engineering, 140(4).

[2] Giglioli, S et al. (2020). Source apportionment assessment of marine sediment contamination in a post-industrial area (Bagnoli, Naples). Water 2020, 12, 2181.
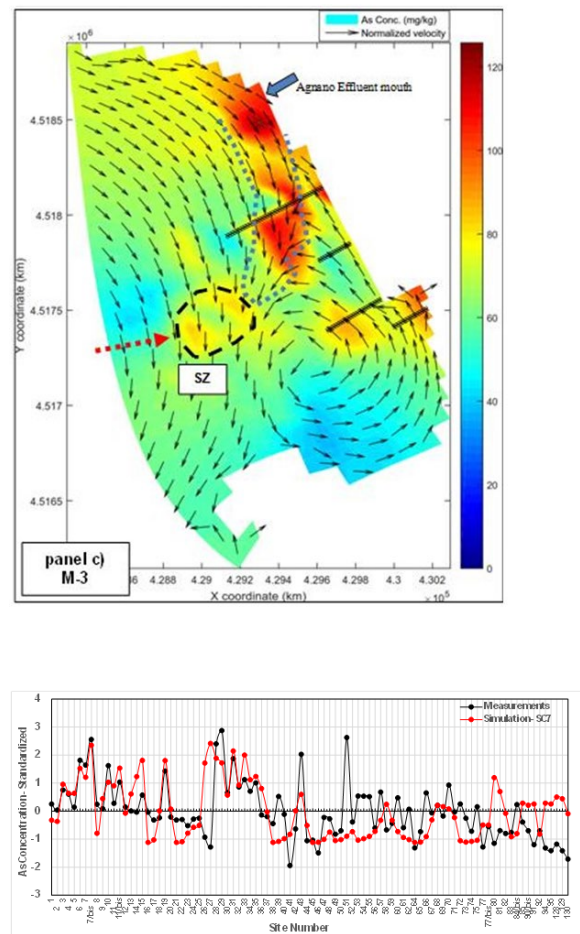